\title{
A MODELLING APPROACH TO THE HUMAN PERCEPTION OF SPATIAL ORIENTATION
}

\author{
Rafał LEWKOWICZ \\ Military Institute of Aviation Medicine, Simulator Study and Aeromedical Training Division, Warsaw, Poland
}

Source of support: Statutory activity of WIML.

Author's address: R. Lewkowicz, Military Institute of Aviation Medicine, Simulator Study and Aeromedical Training Division, Krasińskiego 54/56 Street, 01-755 Warsaw, Poland, e-mail: rlewkowicz@wiml.waw.pl

Introduction: In comparison to high level of knowledge of aircraft dynamics, the knowledge of a pilot in the human - aircraft system still appears to be insufficient. There have been a wide variety of studies and models describing the human's behavior and perception, especially in the flight environment. However, only few of them concern the dynamics of spatial orientation perception. This article deals with one of the most important aspects of aviation physiology. The aim of this paper is to consolidate information on the methods for modelling of the human perception of spatial orientation. This knowledge could be useful for further model's development.

Methods: Systematic review, including publications, conference materials, chapters in books, diploma theses, doctoral dissertations and reports available in electronic databases.

Results: Most of the models of the human perception of spatial orientation currently use one of three techniques for perception estimating: state observer, Kalman's filter and Bayesian estimation. These models are able to mimic orientation perceptions, linear and circular vection, rotation and acceleration in the light, as well as estimate vestibular-ocular reflex.

Figures: 6 - Tables: 1 - References: 142 - Full-text PDF: http://www.pjambp.com • Copyright (C) 2016 Polish Aviation Medicine Society, ul. Krasińskiego 54/56, 01-755 Warsaw, license WIML• Indexation: Index Copernicus, Polish Ministry of Science and Higher Education 
Conclusions: The methods for modelling the perception of spatial orientation could be useful in better understanding of the human's natural ability to determine and maintain the position of the body in relation to the surrounding environment. A multi-sensory model of the human perception of spatial orientation is a tool that could be helpful for recognizing misperceptions during active and passive motion, as well as in other areas related to e.g. motion sickness.

Keywords: spatial orientation, perception, modelling, self-motion perception, vestibular system

\section{INTRODUCTION}

Spatial orientation defines the human's natural ability to maintain his/her body orientation and/ or posture in relation to the surrounding environment (physical space) at rest and during motion. Good spatial orientation relies on the effective perception, integration and interpretation of visual, vestibular (organs of equilibrium located in the inner ear) and proprioceptive (receptors located in the skin, muscles, tendons, and joints) sensory information. In the central nervous system (CNS) the integration, processing, and interpretation these information are conducted. An ability to maintain spatial orientation is very important, especially during flight. The environment of flight is unfamiliar to the human body, creating sensory conflicts and illusions that make spatial orientation difficult. Spatial orientation in flight is sometimes impossible to achieve because numerous sensory stimuli (visual, vestibular, and proprioceptive) vary in magnitude, direction, and frequency. Any differences or discrepancies between visual, vestibular, and proprioceptive sensory inputs result in a sensory mismatch that can produce illusions and lead to spatial disorientation (SD). Stimulation of the vestibular system, e.g. by subthreshold angular accelerations causes pilot's misperceptions and his/her incorrect reactions. It leads to flight accidents caused by the loss of spatial orientation [101], that are among the most dangerous one's, and often lead to the death of crews and huge financial losses $[4,27,40,41,59,102]$. Even the spatial disorientation is sometimes recognized by pilots it causes the temporary loss of situational orientation, which reducing the effectiveness of the performed task $[22,72]$.

While the structure and activity of organs involved in maintaining spatial orientation have been quite well understood $[5,89,92,106,127,128]$, the process of integrating the response from these organs into the CNS and creating the spa- tial orientation perception is still the subject of numerous theoretical and experimental research $[8,26,29,30,64]$. Direct measurement of physical quantities within the vestibular system is limited and experimentally demanding, e.g. in vivo measurements $[55,105,109]$. These limitations have introduced an open field for theoretical considerations including, i.a., in vitro modelling $[39,90,91]$. A similar problem occurs when signals in CNS are measured. For this reason, in order to understand how CNS integrates sensory signals, numerous studies $[9,11,47,68,74,129]$ focusing on modelling the human perception of spatial orientation have been conducted. First of them were oriented towards modelling of perception only to the simple case of Vertical Axis Rotation (VAR) [70]. At the beginning, the weakening of the perceived motion during a prolonged rotation was attributed to the dynamics of the semicircular canals of the vestibular system. In the 1970s the knowledge of semicircular canal [44] and otolith organ models [37], was significantly improved, due to studies the dynamic of the vestibular system. As a result, it turned out that the course of perception in time does not depend only on this dynamics. Study of the Vestibular-Ocular Reflex (VOR) [44] has shown that by processing the input signals of semicircular canals, CNS extends the dynamic range of motion perception by increasing the reflex time constant. This phenomenon is commonly known velocity storage. At that time, an otolith receptors testing was also conducted by Mayne [71], who noted that these receptors reacts unambiguously to both gravitational and linear acceleration. Therefore, the author stated that the dynamics of somato-gravitational illusion is connected with the mechanism of motion signal processing in CNS, which uses both linear and angular acceleration to estimate the direction of the Earth's acceleration vector. 
The most common spatial orientation models in literature are based on the vestibular system $[8,16,48,71,73,75,135]$. Merfeld et al. [77] divided these models into two categories. The first category, so-called "classical systems models" are models that use classical control theory to model the dynamics of vestibular system's receptors. Many researchers $[43,45,49,72,110,113,134]$ have used this technique to describe the response of vestibular system and VOR estimations. These models did not contain internal models of vestibular receptors and did not include CNS processing. The second category of models was called "observer theory models", which use optimal control theory to estimate spatial orientation. This category was introduced by Young [136] and extended by Oman [93]. These models were designed to explain how CNS integrates sensory information in order to estimate spatial orientation. These models assume that the CNS contains internal models of vestibular receptors and body dynamics, as well as certain physical relationships between them. Currently, three types of internal models - CNS models can be distinguished, which construction was based on:

- an optimal estimator approach using Kalman filter techniques, introduced by Borah et al. $[11,13]$, and expanded by Pommellet [103], Bilien [9], Merfeld and Zupan [78], and Selva [116];

- a constant gain estimator, proposed by Merfeld et al. [77], and

- the sensory weighing technique proposed by Zupan et al. [142].

This article presents applied approaches in the modelling of the human perception of spatial orientation. Special attention was paid to models based on state observer theory, which are the most commonly used models in a studies.

\section{Classical systems models}

Probably Mayne [71] developed the first model, for which the theory of classical control was used. He proposed a three-dimensional model of human spatial orientation based on the vestibular system. For processing the signals from otolith receptors and estimating the direction of the gravitational and linear acceleration vectors, the author used a low and high-pass filter, respectively. The method proposed by Mayne [71] was the basis of Grissett's [49] spatial orientation model and the model used by McGrath et al. [72]. Robinson [113] and Wearne [134] also used the Mayne's model, expanding its functionality to include the possibility of estimating optokinetic nystagmus (OKN) and VOR, induced by kinetic stimulus. A similar study with the Mayne's model was conducted by Raphan et al. [110]. Researchers have included into their model a velocity storage mechanism. Ormsby [98] and Ormsby and Young $[99,100]$ developed a models which was only based on the response of the vestibular system receptors. The authors modeled the dynamic interaction of angular velocity and specific gravito-intertial force (GIF), and they used this model, i.a. to estimate illusion related to the perception of static tilt.

\section{Observer theory models based on Kalman filter}

Borah et al. $[11,13]$ were probably the first, who have applied steady-state Kalman Filter (KF) techniques in modelling the human perception of spatial orientation. They included models of visual and vestibular system dynamics and a stimulus transformations from the Earth-fixed reference system to the head-fixed coordinate frame. The model was consistent with the human reaction to the following vestibular and visual-vestibular motion stimuli: circular vection, VAR, and somatogravitational delusion of inclination during linear acceleration in the dark. To adapt the model to calculations for large head tilt (for which the transformation of velocity and acceleration vectors from the Earth reference system to the headfixed coordinate system becomes non-linear), Pommellet et al. [103] generalized the Borah's model using a non-linear KF version, known as Extended Kalman Filter (EKF). The transformation of coordinates between reference systems was conducted with use of quaternions. However, results obtained from the EKF Pommellet's model [103] showed numerical instability in the estimation of quaternions, especially for the more complex rotational profiles with large angular values of head tilt. Bilien [9] had encountered similar problems of numerical instability when he conducted a study a response to Coriolis' illusion, that was estimated with use of vestibular part of the EKF model. An implementation of the stable Borah's model was developed by Kynor [62]. This model estimated responses to non-linear, and high values of head tilt. In 2009, Selva [116] developed a stable Unscented Kalman Filter (UKF) version of the Borah's model. The author used both EKF and UKF filtering techniques to estimate the human perception of spatial orientation. 


\section{Observer theory models based on state observer}

In 1993 Merfeld et al. [77], using a modelling approach in accordance with Luenberger's theory [67], proposed a non-linear one-dimensional model of the human perception of spatial orientation. The construction of the Merfeld's model [77] was based on the concept illustrated in Figure 1. According to this concept, the model of spatial orientation perception is divided into two parts: the model of the physical world and the CNS model, that is represented by so-called internal model. The model of the physical world describes the dynamics of physical sensors (three semicircular canals and two otolith organs), while the internal model represents the sensory signals processing in the CNS.

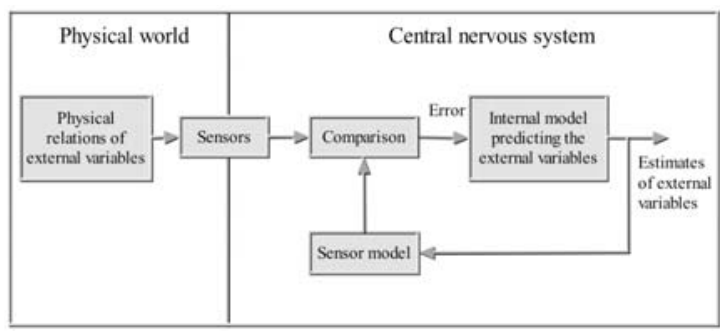

Fig. 1. The outline of the concept of the model of the human perception of spatial orientation [43].

\section{Vestibular organ model - physical world model}

The model of the physical world (fig. 2) consists of semicircular canals and otolith organs (utricle and saccule) models. The dynamics of these receptors are described by the second order differential equations. The most popular mathematical model describing the dynamic of semicircular canals is the model proposed by Steinhausen [123]. This model is in the form of a bandwidth filter, for which the lower cutoff frequency was determined by a long time constant and the upper cutoff frequency was determined by a short time constant $[25,123]$. Between these two boundary frequencies (lower, and upper), the model predicts that endolymph moving under the influence of the head angular acceleration produces a displacement of the cupula. This displacement is directly proportional to the head angular velocity. Mayne $[70,71]$ noticed, that in the range $0.5-5 \mathrm{~Hz}$ of head angular velocity (range includes the frequencies that occur during natural head movements in the human's everyday life), the displacement of the endolymph and the cupula is a measure of the angular velocity than angular acceleration. The mathematical model proposed by Grant and Best [46] is often used to analyze the dynamic of otolith organs (utricle and saccule). The review of physical and mathematical models of the vestibular system receptors and physiological phenomena accompanying their stimulation can be found in paper [65].

\section{CNS model - internal model}

The concept of an internal model was developed in the 1960s, in the field of control engineering, and was used to estimate the orientation and position of a vehicle for autonomous inertial navigation. The internal model (fig. 2) is an integral part of the of estimation techniques theory, such as the state observer theory and the optimal control theory. Since the 1970s, this concept has attracted attention in the field of neurology, starting with models of motion sickness, e.g., Reason [112], Oman [93-95], for the model of human spatial orientation, e.g., Merfeld et al. [77], Borah et al. [11,12], Zupan et al. [141] and Newman [84]. On the basis of the research in the field of body motion perception, it was assumed that CNS possessed knowledge about the dynamics of receptors, which detect the position and movement of the body, as well as certain physical relations between them. According to the model shown in Figure 2, the input signal vector of an internal model is the feedback signal. This signal is determined from the difference in output signals of physical receptor models (model of the physical world) with output signals of receptor models in CNS. The feedback signal is then weighed using experimentally selected gain parameters (fig. 2, triangular blocks) and re-entered into the internal model. Estimation in the internal model is done according to the adopted estimation technique (state observer, KaIman filter or Bayesian estimation). The states that were estimated in this way correspond to the human perception of spatial orientation.

The model (fig. 2) was extended [77] with additional internal estimates of the direction and values of gravitational vector. In the next step, the dynamics of semicircular canals and otolith organs were extended to three dimensions, while the transformation between the head-fixed coordinate system and the Earth-fixed reference system were realized on the basis of quaternions. Selva [116] has shown, that Merfeld's model [77] is well suited for estimating orientation and position also for large head tilts, while the Borah's model [13] is not recommended for use under such conditions. Nevertheless, the researcher found, that for the head upright, the angular velocity storage and the 


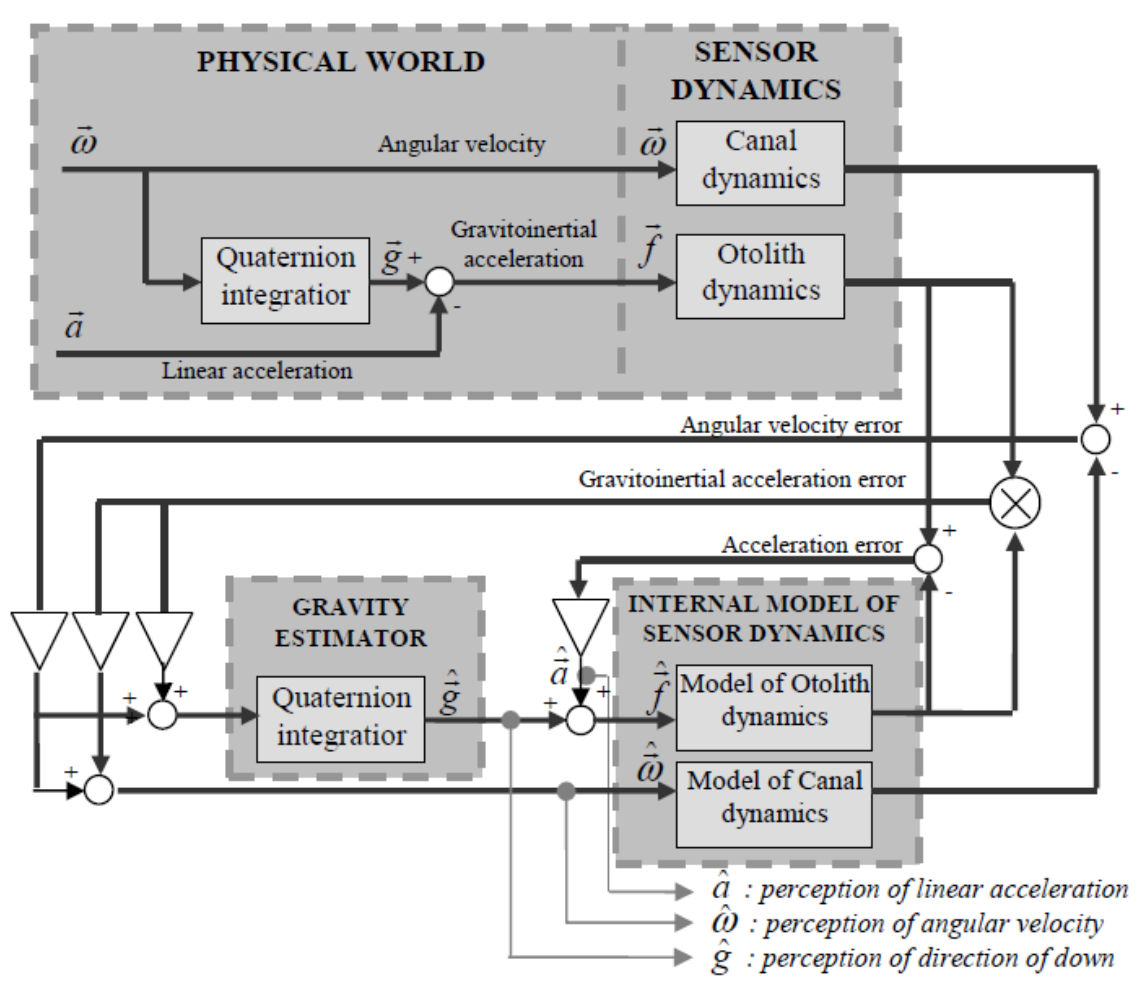

Fig. 2. The scheme of Merfeld's model based on a state observer [77].

somato-gravitational illusion derived from the KF Borah's model [13] and the Merfeld's model [77], are in high compatibility.

Recent cognitive research in the field of internal representation of sensorimotor functions in CNS has been carried out, among others, by Kawato [58], Merfeld et al. [79], Angelaki et al. [2], Green et al. [48], Kording \& Wolpert [60], Kuo [61] and Nooij et al. [88]. The key feature of an internal model is so-called "reafference" principle, which helps to explain the regulation and interaction of CNS internal signals with signals from organs responsible for coordinating body movements. Cullen et al. $[33,34]$ demonstrated some of the neurophysiological correlations of "reafference" and other functions of the CNS model, especially for the adjustment of vestibular reflexes, e.g. VOR.

\section{Development of the state observer models}

Haslwanter et al. [53] have extended the Merfeld's model by including the alternative model of otoliths with a high pass filter of the linear path of VOR, that was originally proposed by Dai et al [35]. This solution made it possible to estimate the VOR for a large angle of head tilt $\left(>45^{\circ}\right)$ during Off-Vertical Axis Rotation (OVAR). In 2002 Merfeld et al. [78], based on their experience from previous research [77], proposed a model of integrating sensory sig- nals in CNS. This model (fig. 3) has been validated on the basis of the results of experimental studies using monkeys $[76,77]$. By empirical regulation of four internal weighted parameters $\left(k_{\phi}, k_{\phi \omega}, k_{\omega}, k_{\alpha}\right)$, this model has the ability to predict the response to a wide range of motion stimuli, including VAR and OVAR.

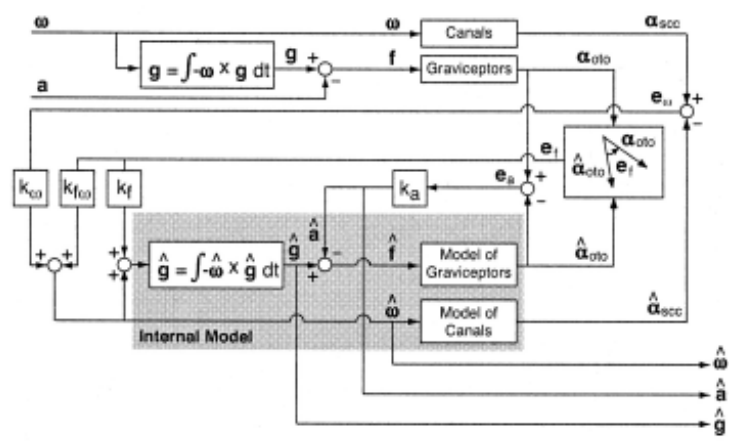

Fig. 3. Diagram of the model of integrating sensory signals in CNS, proposed by Merfeld et al. [78].

It is known, that every linear accelerometer is not able to distinguish the direction of the gravitational vector from linear acceleration vector. This problem also applies to the otolith organ and is commonly referred to as gravito-inertial acceleration (GIA). The above mentioned problem of sensory data interpretation occurs when 
the CNS tries to use the otoliths signal to calculate the head position and orientation relative to the Earth's gravity. The otoliths therefore provide ambiguous information, given that the recorded acceleration can be generated both by translational motion and by changing the head's orientation in relation to the Earth [1]. Thus, the problem of gravito-inertial distribution of GIA must be solved by the CNS using additional information. For this purpose Merfeld et al. [78] proposed including in the model three types of errors $e_{\omega^{\prime}} e_{f}, e_{\mathrm{a}}$. These errors are determined from the difference in sensor response (fig. $3, \alpha_{\text {SСC }}$ and $\alpha_{\text {Ото }}$ ) and their estimated values (fig. 3, designation with a roof " $\wedge$ "). In order to minimize sensory conflict in the form of $e_{f}$ and $e_{a}$ errors in the circuit of otolith organ processing, two weighted constant $k_{\mathrm{f}}$ and $k_{\mathrm{a}}$, acting as a gain in the feedback loop (fig. 3 ) have been included.

In subsequent years the Merfeld's model (fig. 3) has been validated and extended in the Vingerhoets et al. [131,132] and Newman [84] studies. The tests $[3,24]$ carried out in real helicopter flights and in the vertical motion simulator (VMS) showed a fundamental difference in the human ability to correctly interpret inertial acceleration signals that acting along the direction of the gravitational force. The subjects who participated in this studies were not able to correctly indicate a value or direction of motion, often leading to an incorrect phase estimation, even of 180 degrees [24]. For modelling these large phase and error values of vertical motion perception, Vingerhoets et al. [132] included into the human spatial orientation model a leaky integrator with a time constant $\tau=0.04$. This model modification made it possible to minimize vertical component of he estimated error of acceleration. In further study, Vingerhoets et al. [131] took into account both the dynamics of the leaky integrator from previous studies [132] and the weighted vector, which allows estimating a static Subjective Visual Vertical (SVV).

In the previous spatial orientation models $[77,78,84,107,108,131,142]$ all components of the error vector $e_{a}$ were weighed by the same gain parameter $k_{a}$ (fig. 3). Clark [28] differentiated the gains for accelerations acting along the axis of the coordinate system associated with the otolith organ. In the linear acceleration feedback loop, the researcher included two independent gains: $k_{\text {au }}$ and $k_{\text {au }} \perp$, separating the accelerations acting in the utricle plane from the accelerations occurring outside this plane. The gain of the error vector $e_{a}$ (fig. 3) for accelerations acting outside the plane of the utricle remained unchanged $k_{\mathrm{au}} \perp=-4.0[78,84,131]$, while the value of the additional parameter $k_{\mathrm{au}}=-2$ was determined experimentally [28]. Most of the above mentioned Merfeld's model modifications allowed the prediction of angular velocity and linear acceleration, but did not allow the estimation of the position of the head in space. To achieve this, Newman [84] extended the Merfeld's model [77], by including the elements, which were marked in Figure 4 with a darker colour blocks and letters from $A$ to $F$. The changes in the model structure mean: $A$. Transformation from head to limbic coordinate system, B. Leakage integrator for linear velocity estimation (Merfeld et al. [77] included a similar integrator to obtain a velocity for the VOR translation component), $C$. integrator to the position estimation, D. estimated azimuth, E-F. additional feedback gains $k_{\omega f}$ and $k_{1}$. The weighted parameters of the model (described in the dark blocks) have been determined by matching estimated perception with experimental data from tests on humans and animals (tab. 1). The topology of the Newman's model [84] is similar to model developed by Haslwanter et al. [53], extended with additional state estimates (position $\mathrm{x}$ and velocity $v$ ) necessary for estimation of displacement and visual interaction.

Numerous reports $[52,96]$ suggests, that the estimates of azimuth and direction originate in limbic areas of the brain, including hippocampus, thalamus and medical entorhinal cortex. Newman [84] used the limbic coordinate system in his model (fig. 4, designation A). The horizontal plane of the limbic coordinate system is perpendicular to the direction of estimated gravity and acts as human's natural plane of 2D navigation. In order to determine the perceived linear velocity, a leaky integrator (fig. 4, designation B) was included. A method for estimating the position and linear velocity perception in the horizontal plane has been determined quite precisely for the amplitude and frequency range of human motion $[81,82,115]$. For the motion perceived in this plane a time constant integrator is equal to $\tau=16.67$. This value differs significantly from the time constant associated with the actual or expected direction of vertical motion ( $\tau=1.0$ for vertical plane). The standard integrator (fig. 4, designation C) was implemented by Newman [84] to determine the estimated position. The transformation of coordinates between reference systems was conducted with use of quaternions (fig. 4, designation D). The transfor- 
mations made it possible to determine the perceived orientation with respect to the Earth. The last supplement of the vestibular model included by Newman [84] is two additional weighted parameters $k_{\text {of }}$ and $k_{1}$ (fig. 4 , designation E-F). The first parameter $k \omega f$ with a value of 1.0 allows for user control over the influence of angular velocity on the rate of change of gravity. This parameter was added to match the model's estimates to the Tilt-Gain and Tilt-Translation experimental studies. The second parameter $\mathrm{k}_{1}$ is a function of the angular velocity residual weighting parameter $k_{1}=k_{\omega}$ / $\left(k_{\omega}+1\right)$ and was required to make the loop gain of the angular velocity feedback loop unity [84]. Merfeld et al. $[77,78]$, for the value $k_{\omega}=3$ set the parameter value $k_{1}=0.75$. This gain was intentionally set to mimic the $70 \%$ angular VOR response for eye movement data yet is inconsistent with perceptual responses for many simple experiments (i.e. static tilt, constant velocity yaw rotation), where the initial response to sudden head movements is veridical [84]. The above-mentioned Newman extensions in the Merfeld's model [77] were essential for the implementation of additional information from visual sensors (described in detail later in the article). As a result of the conducted tests, Newman demonstrated the conformity of the obtained results with the results described in the studies of Haslwanter et al. [53], Merfeld \& Zupan [78] and Vingerhoets et al. [131,132]. These results were also found to be in line with the results of the KF Borah's model [11], which were determined for simple visual and vestibular profiles of linear and rotational motion. Developed by Newman [84] the model of the human perception of spatial orientation was incorporated into the work of Small et al. $[117,118,120]$, creating the Spatial Disorientation $\vec{a}$

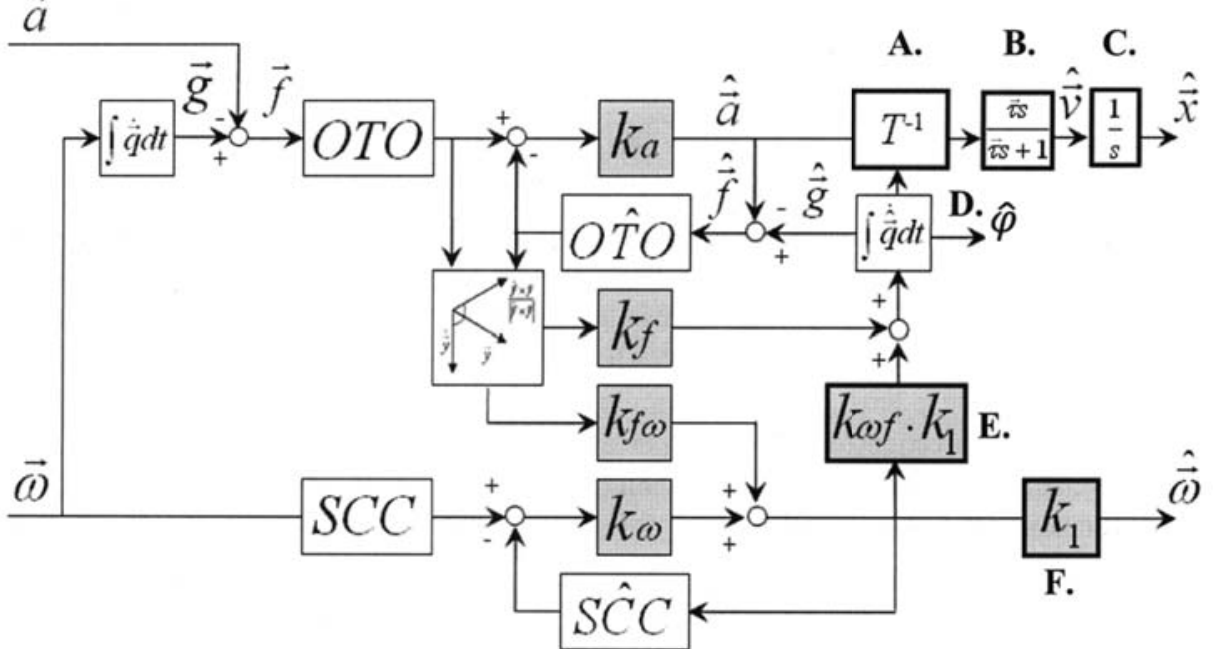

Fig. 4. The extended spatial orientation model based on the vestibular system [84].
Analysis Tool. Similar tool was developed by Creare Inc. under the name The Disorientation Analysis and Prediction System. In this tool the EKF model developed by Kynor [62] was used to analyze the phenomenon of loss of spatial orientation.

The validation studies carried out on the models of spatial orientation perception have been presented in Table 1. These studies were divided in terms of the method of estimating spatial orientation: based on a state observer and the KF filter.

\section{Visual-vestibular model of the human perception of spatial orientation}

In a literature there are two groups of models of the human perception of spatial orientation. The first group consists of simple visual-vestibular models used for estimating the motion perception $[110,113,122,140]$, and the second group consists of more complex models enabling estimation of both motion and orientation $[16,18,69,77,84,97,111,142]$. A few models $[30,80,133,141]$ make it possible to estimate the spatial orientation in response on a stimulus in the form of yaw rotation about an Earth-horizontal axis. This group includes a model based on the sensory weighing method developed by Zupan et al. [141,142]. The researchers used an idiotropic vector (an internal mechanism that drives perceptions in the direction of a person's own longitudinal axis) to estimate correct perception of position and motion.

In the work on modelling the human spatial orientation, it is worth mentioning a study of Laurens and Droulez's [63], who have constructed a model based on the method of Bayesian processing. This processing is carried out according to the probabilistic Bayesian estimation algorithm, which recurrently updates the previous system state with 
Tab. 1. Validation studies and weighting parameters of state observer and KF/EKF models $[87,116]$.

\begin{tabular}{|c|c|c|c|c|c|c|c|c|c|c|c|c|c|}
\hline \multirow[b]{2}{*}{ Models } & \multicolumn{7}{|c|}{ Incentives used for model validation } & \multirow[b]{2}{*}{ 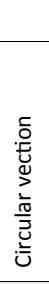 } & & \multicolumn{4}{|c|}{ Weight parameters values } \\
\hline & $\stackrel{\frac{c}{s}}{\lessgtr}$ & $\stackrel{\frac{\alpha}{4}}{\partial}$ & 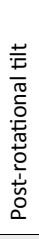 & 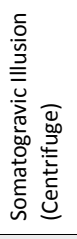 & 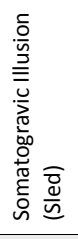 & $\begin{array}{l}\stackrel{+}{E} \\
\overline{\bar{O}} \\
\propto\end{array}$ & $\frac{\stackrel{n}{\frac{0}{0}}}{\stackrel{0}{0}}$ & & 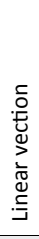 & $\mathrm{k}_{\mathrm{a}}$ & $k_{f}$ & $k_{\omega f}$ & $\mathrm{k}_{\omega}$ \\
\hline \multicolumn{14}{|l|}{ Observer } \\
\hline Merfeld [76] & $x$ & $\mathrm{x}$ & $x$ & - & - & - & - & - & - & -0.9 & 2 & 20 & 3 \\
\hline Haslwanter [52] & - & $\mathrm{x}$ & - & - & - & - & - & - & - & -1 & 10 & 1 & 1 \\
\hline Merfeld [78] & - & - & - & $x$ & - & $\mathrm{x}$ & - & - & - & -2 & 2 & 2 & 3 \\
\hline $\begin{array}{l}\text { Vingerhoets } \\
\text { [131] }\end{array}$ & - & $\mathrm{x}$ & - & - & - & - & - & - & - & -4 & 2 & 8 & 8 \\
\hline $\begin{array}{l}\text { Vingerhoets } \\
\text { [130] }\end{array}$ & - & $x$ & - & - & - & $x$ & - & - & - & -4 & 2 & 8 & 8 \\
\hline Newman [84] & $x$ & $\mathrm{x}$ & - & $x$ & $x$ & - & $x$ & $x$ & $x$ & & & & \\
\hline Small et al. [116] & $x$ & $x$ & $x$ & $x$ & $x$ & $x$ & $x$ & $x$ & $x$ & & & & \\
\hline $\begin{array}{l}\text { Newman et al. } \\
\text { [87] }\end{array}$ & $x$ & $x$ & $x$ & $x$ & $\mathrm{x}$ & $x$ & $x$ & $x$ & $x$ & -4 & -4 & 8 & 8 \\
\hline \multicolumn{14}{|l|}{ KF/EKF } \\
\hline Borah $[11,13]$ & $x$ & - & - & - & $x$ & - & - & $x$ & $x$ & & & & \\
\hline Pommellet [102] & $x$ & - & - & $x$ & $x$ & - & - & $x$ & $x$ & & & & \\
\hline Billien [9] & - & - & - & $x$ & - & - & $x$ & - & - & & & & \\
\hline Kynor [61] & $x$ & - & - & $x$ & $\mathrm{x}$ & - & - & - & - & & & & \\
\hline Selva [115] & $x$ & - & - & - & $\mathrm{x}$ & - & $\mathrm{x}$ & $\mathrm{x}$ & - & & & & \\
\hline
\end{tabular}

the appearance of new observations. This threedimensional vestibular model was successfully tested in numerical computational experiments. As a result, the model proved to be effective in estimating VOR.

In the following part of the article, an attention was paid to one of the models mentioned above (Newman's model [84]) and at the same time a readers are encouraged to read the description of other models included in the work $[56,87]$. Newman [84] expanded his model based on the vestibular system (fig. 4) to a visual-vestibular model of the human perception of spatial orientation (fig. 5).

The author assumed that the visual sensor is able to receive four visual signals from the environment. These vectors are: position $x_{v^{\prime}}$ linear velocity $\dot{x}_{v}$ angular velocity $\omega_{v}$ and acceleration of gravity $\mathrm{g}_{\mathrm{v}}$. In order to ensure consistency with the limbic coordinate system (fig. 4, designation A), the visual signals are transformed into corresponding sensory processing systems. To transform the visual signals of gravity and angular velocity from Earthfixed coordinate system to head-fixed coordinate system the matrix $T$ was used. In the case of the visual signals of position and linear velocity the matrix $\mathrm{T}^{-1}$ was used to conduct a transformation from head-fixed to limbic coordinate system. Each of the above signals are processed by the suitable model of the visual sensor VIS $\left(\right.$ where: $i-x_{v^{\prime}} \dot{x}_{v^{\prime}} \omega_{v^{\prime}}$ $g_{v}$ ). The response $a_{i}$ from model VIS is compared with the signal $a_{i}$ (designation with " $\wedge$ ") estimated by the internal model of this sensor. The result of

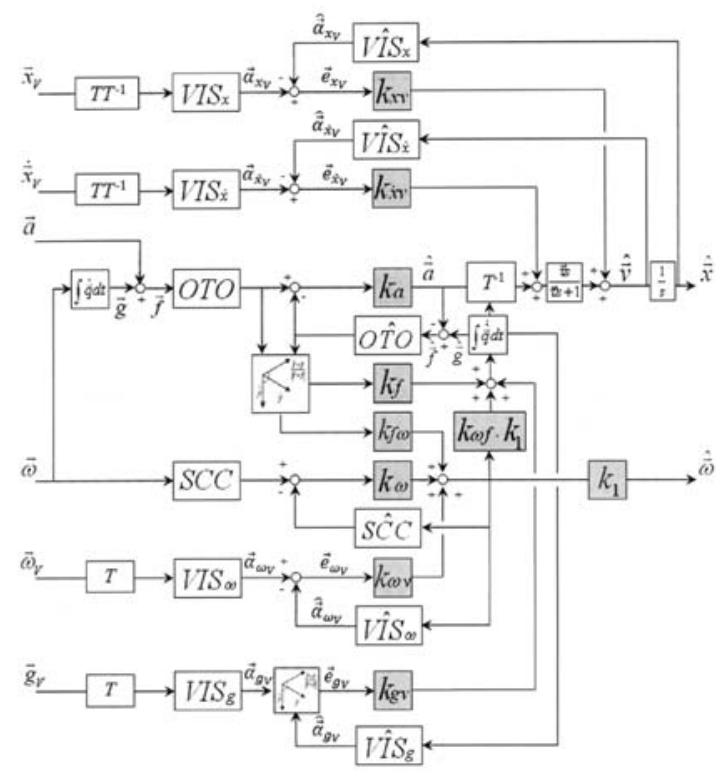

Fig. 5. Visual-vestibular model of the human perception of spatial orientation [84]. 
comparison is sensory conflict $\mathrm{e}_{\mathrm{i}}$, that is controlled by the gain parameter $\mathrm{k}_{\mathrm{i}}$, and then, according to the structure of the classic Luenberger observer [67] is added to the derived estimated signal (fig. 5). Newman [84] adopted a simplified model of the visual system $\mathrm{VIS}_{i}$, and described its dynamics with an unity matrix. In fact, the visual impression of self-motion is approximately proportional to the velocity of the motion visual stimulus in the peripheral field of view, until a certain saturation level is reached $[7,23,36]$. The effectiveness of this stimulus depends on its spatial frequency, contrast and resolution of its components [54]. The saturation levels during VAR and linear vection were determined at approximately $60 \%$ and 1 $\mathrm{m} / \mathrm{s}$, respectively [139]. Although the visual flow in a peripheral field of view may not instantly trigger a self-motion sensation, the movement of the field is detected almost immediately after a short delay of neural transmission. According to Janssen [57], the vision model can be modelled using a low pass filter with a $0.2 \mathrm{~Hz}$ cut-off. Newman's model [84] (fig. 5) is able to mimic orientation perceptions, linear and circular vection, rotation and acceleration in the light. This model is currently used in the study of the human perception of spatial orientation in the altered gravitational acceleration (hyper-gravity i.e., $>1$ Earth g normally experienced and hypo-gravity i.e., $<1$ Earth g) $[30,31,87]$.

\section{DISCUSSION}

Over the past several decades, mathematical models of the human perception of spatial orientation based on the concept derived from the estimation theory have been widely used in vestibular system studies. Most of these models use one of the three estimation techniques: Bayesian estimation $[60,63,68]$, Kalman's filter (KF)[11,13,103] with its variations $[9,116]$ and the state observer
$[29,30,74,77,84,85,97]$. Some models combine these techniques to create hybrid models. Among others, Groen et al. [50] developed a visual-vestibular model in which they used a state observer to estimate perception, and low pass filter to solve ambiguity in determining the perceived tilt-translation. However, the most commonly used techniques in modelling the human of spatial orientation include a state observer and optimal control theory. A models based on state observer or KF and its variations are widely described in studies of MacNeilage et al. [68], Selva [116], Newman [84], and Young [135]. In Figure 6 shown a history of development the models of velocity storage, state observer and optimal control, that was illustrated by Newman's [87].

The models of the human perception of spatial orientation presented in the article often become the core of motion sickness models $[6,10,14-17,19-21,93,94]$. The models of spatial orientation perception have ability to determine the perceived human position and motion, as well as Subjective Vertical (SV). These models are also used in the area of flight safety as a tool supporting the research and investigation of aviation accidents and mishap $[62,83,85,86,114,117,119,120]$. Apart from indicating the perceived motion and position, the models of spatial orientation, also provides information about the possibility of illusions occurrence, that leads to pilot's loss of spatial orientation. These models are also used in the algorithm synthesis procedure for optimal control of the simulator motion system [124-126,130]. The more complex versions of these models are used to assess the acceleration fidelity of these motion systems [38,66,104].

In the models of spatial orientation perception a some simplifications were included by their authors. These simplifications are mainly due to the insignificant influence of the modelled phenom-

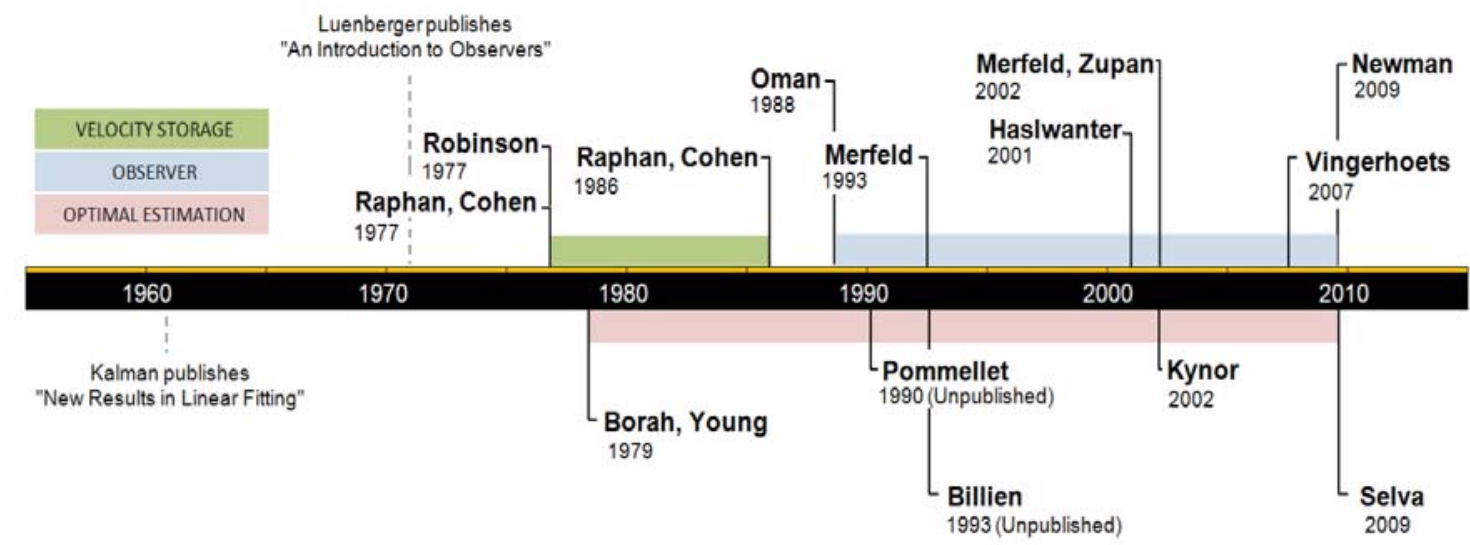

Fig. 6. Timeline of development of velocity storage, observer and optimal control perception models [87]. 
enon on the result of numerical simulations or due to the insufficient knowledge of this phenomenon. Some of these simplifications concern:

1. Omitting the occurrence of the phenomenon of habituation and restitution of the vestibular system. Modelling of adaptation and habituation has been a subject of several studies [32,92,121,138], however they have not been included in the models of spatial orientation perception [84,87]. In case of the restitution process [42], no models describing this phenomenon were found.

2. An assumption of linearity of the vestibular system receptors model, that limits its application to the following frequency ranges:

- for angular velocity, which includes natural head movements in human everyday life: frequencies from 0.01 to $5 \mathrm{~Hz}$ $[5,51,71]$,

- for linear acceleration: frequency from 0.001 to $0.02 \mathrm{~Hz}$ [137].

3. Dynamic of the visual system, that has been described with a unity matrix [84]. In this way, a saturation limits and the distinction between central and peripheral fields of view has been omitted [11,103].

4. Insufficient model validation for accelerations occurring during flight (hyper-gravity and hypo-gravity).

\section{CONCLUSIONS}

This article deals with one of the most important aspects of contemporary aviation physiology. The developing and applying the model of the human perception of spatial orientation results from the need to better understand a pilot's physiological limitations, in particular:

- individual susceptibility to vestibular illusions,

- a sensory conflict adversely affecting the pilot's spatial orientation,

- possible disturbances the perception of posture and motion, causing imbalance and motion sickness.

The model of spatial orientation perception can provide answers to questions concerning sensory sensations experienced by a pilot in a complex acceleration field [87]. The model can also be used in the following areas:

- development of pilots' training programs in the field of loss of spatial orientation and visualvestibular system limitations in flight,

- determination of the effectiveness of flight profiles, that were defined for training purposes in the SD simulators,

- development the effective methods for using modern, technically advanced flight simulators for the selection of candidates and assessment of suitability for the pilot's profession.

\section{AUTHORS' DECLARATION:}

Study Design: Rafał Lewkowicz; Data Collection: Rafał Lewkowicz; Manuscript Preparation: Rafał Lewkowicz; Funds Collection: Rafał Lewkowicz. The Author declares that there is no conflict of interest. 
R. Lewkowicz - A modelling approach to...

\section{REFERENCES}

1. Angelaki DE, Dickman JD. Spatiotemporal processing of linear acceleration: primary afferent and central vestibular neuron responses. J Neurophysiol. United States; 2000; 84(4):2113-32.

2. Angelaki DE, Shaikh AG, Green AM, Dickman JD. Neurons compute internal models of the physical laws of motion. Nature. England; 2004; 430(6999):560-4.

3. Aponso BL, Beard SD, Schroeder JA. The NASA Ames Vertical Motion Simulator - A Facility Engineered for Realism. In: Royal Aeronautical Society Spring 2009 Flight Simulation Conference. London, UK; 2009. p. 3-4.

4. Bellenkes A, Bason R, Yacavone DW. Spatial disorientation in naval aviation mishaps: a review of class A incidents from 1980 through 1989. Aviat Space Environ Med. United States; 1992; 63(2):128-31.

5. Benson AJ. Interactions between semicircular canals and gravireceptors. In: Recent advances in aerospace medicine. Springer Dordrecht; 1970. p. 249-61.

6. Benson AJ. Motion sickness. In: Ernsting's Aviation Medicine. 2006. p. 459-75.

7. Berthoz A, Pavard B, Young LR. Perception of linear horizontal self-motion induced by peripheral vision (linearvection) basic characteristics and visual-vestibular interactions. Exp brain Res. Germany; 1975; 23(5):471-89.

8. Bertolini G, Ramat S, Laurens J, Bockisch CJ, Marti S, Straumann D, et al. Velocity storage contribution to vestibular selfmotion perception in healthy human subjects. J Neurophysiol. 2011; 105(1):209-23.

9. Bilien V. Modeling human spatial orientation perception in a centrifuge using estimation theory. MSc thesis. [MSc thesis]. Massachusetts Institute of Technology; 1993.

10. Bles W, Bos JE, De Graaf B, Groen E, Wertheim AH. Motion sickness: Only one provocative conflict? Brain Res Bull. 1998; 47(5):481-7.

11. Borah J, Young LR, Curry RE. Optimal estimator model for human spatial orientation. Ann N Y Acad Sci. 1988; 545:51-73.

12. Borah J, Young LR, Curry RE. Optimal estimator model for human spatial orientation. In: IEEE Transactions on Systems, Man and Cybernetics. 1979. p. 800-5.

13. Borah J, Young LR, Curry RE. Sensory Mechanism Modeling. (AFHRL-TR-78-83). Final Report. OH: AFHRL.: DTIC Document; 1978.

14. Bos JE, Bles W. Modelling motion sickness. RTO-MP-20 AC/323(HFM)TP/7. In: Wright-Patterson Air Force Base, editor. RTO HFM Specialists - Meeting on "Models for aircrew safety assesment: Uses, Limitations and Requirements." Ohio: Research and Technology Organisation (NATO); 1998. p. 4.

15. Bos JE, Bles W, Hosman RJAW, Groen EL. The cause of spatial disorientation. RTO-MP-086. In: RTO HFM Symposium on Spatial Disorientation in Military Vehicles Causes Consequences and Cures. La Coruña, Spain; 2002. p. 13.

16. Bos JE, Hosman RJAW, Bles W. Visual-vestibular interactions and spatial (dis)orientation in flight and flight simulation. TNOreport TM-02-C009. Soesterberg, Netherlands; 2002.

17. Bos JEE, Bles W. Theoretical considerations on canal-otolith interaction and an observer model. Biol Cybern. 2002; 86(3):191-207.

18. Bos J, Bles W, Hosman R. Modeling human spatial orientation and motion perception. In: AIAA Modeling and Simulation Technologies Conference and Exhibit. Montreal Canada: American Institute of Aeronautics and Astronautics; 2001.

19. Braccesi C, Cianetti F. Motion sickness. Part I: development of a model for predicting motion sickness incidence. Int J Hum Factors Model Simul. 2011; 2(3):163-87.

20. Braccesi C, Cianetti F, Elia A. Motion sickness. Part II: experimental verification on the railways of a model for predicting motion sickness incidence. Int J Hum Factors Model Simul. 2011; 2(3):188.

21. Braccesi C, Cianetti F, Scaletta R. The use of the PCT index in railway motion sickness incidence evaluation. Proc Inst Mech Eng Part F J Rail Rapid Transit. 2013; 229(4):428-45.

22. Braithwaite MG. Controlling the hazard of spatial disorientation in rotary-wing operations by enhanced training. In: RTO HFM Symposium on "Current Aeromedical Issues in Rotary Wing Operations." San Diego, USA; 1998. p. 19-21.

23. Brandt TH, Dichgans J, Koenig E. Differential effects of central versus peripheral vision of egocentric and exocentric motor perception. Exp Brain Res. 1973; 16:476-91.

24. Bray RS. Visual and Motion Cueing in Helicopter Simulation. Report No. NASA TM-86818. Flight Mechanics Panel Symposium on Flight Simulation. Moffett Field, CA; 1985.

25. van Buskirk WC. Vestibular mechanics. In: Skalak R, Chien S, editors. In Handbook of Bioengineering. McGraw Hill; 1987. p. 31.1-31.17. 
26. Carriot J, Jamali M, Brooks JX, Cullen KE. Integration of canal and otolith inputs by central vestibular neurons is subadditive for both active and passive self-motion: implication for perception. J Neurosci. 2015; 35(8):3555-65.

27. Cheung B, Money K, Wright H, Bateman W. Spatial disorientation-implicated accidents in Canadian forces, 1982-92. Aviat Space Environ Med. United States; 1995; 66(6):579-85.

28. Clark TK. Human Perception and Control of Vehicle Roll Tilt in Hyper-Gravity. PhD dissertation. Massachusetts Institute of Technology; 2013.

29. Clark TK, Newman MC, Oman CM, Merfeld DM, Young LR. Human perceptual overestimation of whole body roll tilt in hypergravity. J Neurophysiol. 2015; 113(7):2062-77.

30. Clark TK, Newman MC, Oman CM, Merfeld DM, Young LR. Modeling human perception of orientation in altered gravity. Front Syst Neurosci. 2015; 9(68):1-13.

31. Clark T, Stimpson A, Young LR, Oman CM, Duda KR. Analysis of human spatial perception during lunar landing. In: Aerospace Conference, IEEE Big Sky, MT. 2010. p. 1-13.

32. Cohen H, Cohen B, Raphan T, Waespe W. Habituation and adaptation of the vestibuloocular reflex: a model of differential control by the vestibulocerebellum. Exp Brain Res. 1992; 90(3):526-38.

33. Cullen KE, Brooks JX, Sadeghi SG. How actions alter sensory processing: reafference in the vestibular system. Ann N Y Acad Sci. United States; 2009; 1164:29-36.

34. Cullen KE, Minor LB, Beraneck M, Sadeghi SG. Neural substrates underlying vestibular compensation: contribution of peripheral versus central processing. J Vestib Res. Netherlands; 2009; 19(5-6):171-82.

35. Dai MJ, Curthoys IS, Halmagyi GM. Linear acceleration perception in the roll plane before and after unilateral vestibular neurectomy. Exp Brain Res. 1989; 77(2):315-28.

36. Dichgans J, Brandt TH. The Psychophysics of Visually Induced Perception of Self-Motion and Tilt. Neurosci. 1974.

37. Fernandez C, Goldberg JM. Physiology of Peripheral Neurons Innervating Otolith Organs of the Squirrel Monkey. I. Response to static tilts and to long-duration centrifugal force. J Neurophysiol. 1976; 39(5):970-84.

38. Gao J, Zheng ST, Li HR. Assessment of Flight Simulator Fidelity for Pitch Task. Key Eng Mater. 2011; 460-461:569-73.

39. Gastaldi L, Sorli S, Pastorelli M. Vestibular apparatus: dynamic model of the semicircular canals. In: Modelling in Medicine and Biology. 2011. p. 223-34.

40. Gibb R, Ercoline B, Scharff L. Spatial disorientation: decades of pilot fatalities. Aviat Space Environ Med. United States; 2011; 82(7):717-24.

41. Gillingham KK, Previc FH. Spatial orientation in flight. Raport No. AL-TR-1993-0022. San Antonio, TX; 1993.

42. Gillingham KK. The spatial disorientation problem in the United States Air Force. J Vestib Res. Netherlands; 1992; 2(4):297-306.

43. Glasauer S, Merfeld DM. Modelling Three Dimensional Vestibular Responses During Complex Motion Stimulation. In: Fetter M, Haslwanter T, Misslich H, editors. Three-Dimensional Kinematics of Eye, Head and Limb Movement. Harwood academic; 1997. p. 387-98.

44. Goldberg JM, Fernandez C. Physiology of peripheral neurons innervating semicircular canals of the squirrel monkey. III. Variations among units in their discharge properties. J Neurophysiol. 1971; 34:676-684.

45. Grant JW, Best WA. Mechanics of the otolith organ-dynamic response. Ann Biomed Eng. 1986; 14(3):241-56.

46. Grant JW, Best WA. Otolith-Organ Mechanics: Lumped Parameter Model and Dynamic Response. Aviat Sp Environ Med. 1987; 58(10):970-6.

47. Green AM, Angelaki DE. Coordinate transformations and sensosy integration in the detection of spatial orientation and self-motion: from models to experiments. Prog Brain Res. 2007; 165:155-80.

48. Green AM, Shaikh AG, Angelaki DE. Sensory vestibular contributions to constructing internal models of self-motion. J Neural Eng. 2005; 2(3):164-79.

49. Grissett JD. Mathematical Model Interaction of Canals and Otoliths in Perception of orientation, translation and rotation. NAMRL Special Report 93-5. Pensacola, Florida; 1993.

50. Groen EL, Smaili MH, Hosman RJAW. Perception Model Analysis of Flight Simulator Motion for a Decrab Maneuver. J Aircr. $2007 ; 44(2): 427-35$.

51. Grossman GE, Leigh RJ, Abel LA, Lanska DJ, Thurston SE. Frequency and velocity of rotational head perturbations during locomotion. Exp Brain Res. 1988; 70(3):470-6.

52. Haslwanter T, Jaeger R, Mayr S, Fetter M. Three-dimensional eye-movement responses to off-vertical axis rotations in humans. Exp Brain Res. 2000; 134(1):96-106. 
53. Held R, Dichigans J, Bauer J. Characteristics of moving visual scenes influencing spatial orientation. Vision Res. England; 1975; 15(3):357-65.

54. Highstein SM, Rabbitt RD, Holstein GR, Boyle RD. Determinants of spatial and temporal coding by semicircular canal afferents. J Neurophysiol. 2005; 93(5):2359-70.

55. Hosman RJAW, Cardullo FM, Bos JE. Visual-Vestibular interaction in motion perception. In: AIAA Modeling and Simulation Technologies Conference. Portland, Oregon; 2011. p. 14.

56. Janssen M. Vestibular Exploration on Advanced Diagnostics and Therapy. PhD Thesis. School of Medical Physics and Engineering Eindhoven Cover; 2011.

57. Kawato M. Internal models for motor control and trajectory planning. Curr Opin Neurobiol. England; 1999; 9(6):718-27.

58. Knapp CJ, Johnson R. F-16 Class A mishaps in the U.S. Air Force, 1975-93. Aviat Space Environ Med. United States; 1996; 67(8):777-83.

59. Kording KP, Wolpert DM. Bayesian integration in sensorimotor learning. Nature. England; 2004; 427(6971):244-7.

60. Kuo AD. An optimal control model for analyzing human postural balance. IEEE Trans Biomed Eng. United States; 1995; 42(1):87-101.

61. Kynor DB. Disorientation Analysis and Prediction System. Final Report AFRL-HE-WP-TR-2002-0179. OH: Final Report AFRLHE-WP-TR-2002-0179, United States Air Force Research Laboratory, Wright-Patterson Air Force Base, OH; 2002.

62. Laurens J, Droulez J. Bayesian modelling of visuo-vestibular interactions. In: Springer Tracts in Advanced Robotics. 2008. p. $279-300$

63. Laurens J, Straumann D, Hess BJM. Processing of angular motion and gravity information through an internal model. J Neurophysiol. 2010; 104(3):1370-81.

64. Lewkowicz R. Modele receptorów narządu przedsionkowego człowieka oraz zjawisk fizjologicznych towarzyszących ich pobudzeniom. Models of the human vestibular system receptors and physiological phenomena accompanying their stimulation (in Polish). Model inżynierskie. 2016; 27(58):83-104.

65. Lewkowicz R. Modelowanie układu przedsionkowego pilota na potrzeby oceny algorytmu sterowania układem ruchu symulatora lotu. Modeling of the pilot's vestibular system for the evaluation of the control algorithm of the flight simulator motion system. (in Polish). In: Mechanika w lotnictwie ML-XVII. Kaziemirz Dolny: PTMTS, ISBN: 978-83-932107-8-7; 2016. p. 247-62.

66. Luenberger DG. An Introduction to Observers. IEEE Trans Automat Contr. 1971; 16(6):596-602.

67. MacNeilage PR, Ganesan N, Angelaki DE. Computational approaches to spatial orientation: from transfer functions to dynamic Bayesian inference. J Neurophysiol. 2008; 100:2981-96.

68. Matsangas P. A linear physiological visual-vestibular interaction model for the prediction of motion sickness incidence. MSc. Thesis. Naval Postgraduate School; 2004.

69. Mayne R. The audiogyral illusion and the mechanism of spatial representation. Bull Math Biophisics. 1952; 14(1):27-34.

70. Mayne R. A systems concept of the vestibular organs. In: Vestibular System Part 2: Psychophysics, Applied Aspects and General Interpretations. Berlin: Springer Berlin Heidelberg; 1974. p. 493-580.

71. McGrath BJ, Rupert AH, Guedry FE. Analysis of spatial disorientation mishaps in the US Navy. RTO-MP-086. In: RTO HFM Symposium on "Spatial Disorientation in Military Vehicles: Causes, Consequences and Cures." La Coruña, Spain: The Research and Technology Organisation (RTO) of NATO; 2002. p. 10-22.

72. Meiry JL. The vestibular system and human dynamic space orientation. PhD dissertation. Massachusetts Institute of Technology; 1965.

73. Merfeld DM. Internal models and spatial orientation. Behav Brain Sci. 2004; 27(3):410-410.

74. Merfeld DM. Modeling human vestibular responses during eccentric rotation and off vertical axis rotation. Acta Otolaryngol Suppl. 1995; 520:354-9.

75. Merfeld DM. Modeling the Vestibuloocular Reflex of the Squirrel-Monkey during Eccentric Rotation and Roll Tilt. Exp Brain Res. 1995; 106(1):123-34.

76. Merfeld DM, Young LR, Oman CM, Shelhamer MJ. A multidimensional model of the effect of gravity on the spatial orientation of the monkey. J Vestib Res. 1993; 3(2):141-61.

77. Merfeld DM, Zupan LH, Gifford CA. Neural processing of gravito-inertial cues in humans. II. Influence of the semicircular canals during eccentric rotation. J Neurophysiol. 2001; 85(4):1648-60.

78. Merfeld DM, Zupan LH. Neural Processing of Gravitoinertial Cues in Humans. III. Modeling Tilt and Translation Responses. J Neurophysiol. 2002; 87(2):819-833.

79. Merfeld DM, Zupan LH, Peterka RJ. Humans use internal models to estimate gravity and linear acceleration. Nature. 1999; 398(6728):615-8. 
80. Mittelstaedt H. A new solution to the problem of the subjective vertical. Naturwissenschaften. 1983; 70(6):272-81.

81. Mittelstaedt ML, Glasauer S. Idiothetic Navigation in Gerbils and Humans. Zool Jahrbucher-Abteilung fur Allg Zool und Physiol der Tiere. 1991; 95(3-4):427-35.

82. Mittelstaedt ML, Mittelstaedt H. Idiothetic navigation in humans: estimation of path length. Exp Brain Res. 2001; 139(3):318-32.

83. Mumaw, R J, Groen EL, Fucke L, Anderson R, Bos JE, Houben M. A New Tool for Analyzing the Potential Influence of Vestibular Illusions. In: ISASI Forum, Journal of the International Society of Air Safety Investigators 49. Augsburg, Germany; 2016. p. 6-12.

84. Newman MC. A multisensory observer model for human spatial orientation perception. PhD dissertation. Massachusetts Institute of Technology; 2009.

85. Newman MC, Lawson BD, McGrath BJ, Rupert AH. Perceptual Modeling as a Tool to Prevent Aircraft Upset Associated with Spatial Disorientation. In: Proceedings of the AIAA Guidance, Navigation, and Control Conference. National Harbor, MD; 2014. p. 1-12.

86. Newman MC, Lawson BD, Rupert AH, Mcgrath BJ. The Role of Perceptual Modeling in the Understanding of Spatial Disorientation During Flight and Ground-based Simulator Training. In: AIAA Modeling and Simulation Technologies Conference. Minneapolis, MN; 2012. p. 1-14.

87. Newman MC, Lawson BD, Rupert AH, McGrath BJ, Hayes AM, Milam LS. A Model of Human Orientation and Self-Motion Perception during Body Acceleration. USAARL Report No. 2016-22. Fort Rucker, AL; 2016.

88. Nooij SAE, Bos JE, Groen EL. Orientation of Listing's plane after hypergravity in humans. J Vestib Res Orientat. 2008; 18(2-3):97-105.

89. Obrist D. Fluidmechanics of semicircular canals - revisited. Zeitschrift für Angew Math und Phys. 2008; 59(3):475-97.

90. Obrist D. Fluid mechanics of the inner ear. Habilitation treatise. University Hospital Zurich and the Institute for Biomechanics ETH Zurich; 2011.

91. Obrist D, Hegemann S, Kronenberg D, Hauselmann O, Rosgen T. In vitro model of a semicircular canal: Design and validation of the model and its use for the study of canalithiasis. J Biomech. 2010; 43(6):1208-14.

92. Oman CM. Influence of Adaptation on the Human Semicircular Canals and the Role of Subjective Angular Velocity Cues in Spatial Orientation. MSc. thesis. Massachusetts Institute of Technology; 1968.

93. Oman CM. A heuristic mathematical model for the dynamics of sensory conflict and motion sickness. Acta Otolaryngol Suppl. 1982; 392:1-44.

94. Oman CM. Motion sickness: a synthesis and evaluation of the sensory conflict theory. Can J Physiol Pharmacol. NRC Research Press; 1990; 68(2):294-303.

95. Oman CM. Sensory conflict in motion sickness: an observer theory approach. In: Pictorial communication in virtual and real environments (2nd ed). 1993. p. 362-76.

96. Onur C. Developing a Computational Model of the Pilot's Best Possible Expectation of Aircraft State Given Vestibular and Visual Cues. MSc. Thesis. Georgia Institute of Technology; 2014.

97. Ormsby CC. Model of Human Dynamic Orientation. PhD dissertation. Massachusetts Institute of Technology; 1974.

98. Ormsby CC, Young LR. Perception of static orientation in a constant gravito-inertial environment. Aviat Sp Environ Med. 1976; 47(2):159-64.

99. Ormsby CC, Young LR. Integration of semicircular canal and otolith information for multisensory orientation stimuli. Math Biosci. 1977; 34(1):1-21.

100. Pancratz DJ, Bomar Jr. JB, Raddin Jr. JH. A New Source for Vestibular Illusions in high agility aircraft. Aviat Sp Environ Med. 1994; 65:1130-3.

101. Poisson RJ, Miller ME. Spatial disorientation mishap trends in the U.S. Air force 1993-2013. Aviat Space Environ Med. United States; 2014; 85(9):919-24.

102. Pommellet PE. Suboptimal Estimator for the Spatial Orientation of a Pilot. MSc. thesis. Massachusetts Institute of Technology, Cambridge, MA; 1990.

103. Pool DM. Objective Evaluation of Flight Simulator Motion Cueing Fidelity Through a Cybernetic Approach. PhD dissertation. Delft University of Technology; 2012.

104. Rabbitt RD, Breneman KD, King C, Yamauchi AM, Boyle RD, Highstein SM. Dynamic displacement of normal and detached semicircular canal cupula. JARO - J Assoc Res Otolaryngol. 2009; 10:497-509.

105. Rabbitt RD, Damiano ER, Grant JW. Biomechanics of the Semicircular Canals and Otolith Organs. In: Highstein SM, Fay RR, Popper AN, editors. The vestibular system. New York, NY: Springer US; 2004. p. 153-201.

106. Rader AA. Motion perception with conflicting or congruent visual and vestibular cues. PhD dissertation. Massachusetts Institute of Technology; 2009. 
107. Rader AA, Oman CM, Merfeld DM. Motion perception during variable-radius swing motion in darkness. J Neurophysiol. 2009; 102(4):2232-44.

108. Rajguru SM, Rabbitt RD. Afferent responses during experimentally induced semicircular canalithiasis. J Neurophysiol. 2007; 97(3):2355-63.

109. Raphan T, Matsuo V, Cohen B. Velocity storage in the vestibulo-ocular reflex arc (VOR). Exp Brain Res. 1979; 35(2):229-48.

110. Raphan T, Sturm D. Modeling the spatiotemporal organization of velocity storage in the vestibuloocular reflex by optokinetic studies. J Neurophysiol. 1991; 66(4):1410 LP-1421.

111. Reason JT. Motion sickness adaptation: a neural mismatch model. J R Soc Med. 1978; 71(11):819-29.

112. Robinson DA. Linear addition of optokinetic and vestibular signals in the vestibular nucleus. Exp brain Res. 1977; 30(23):447-50.

113. Rupert AH, Brill JC, Lawson BD, Woo G. Countermeasures for Loss of Situation Awareness : Spatial Orientation Modeling to Reduce Mishaps. In: Proceedings of the Aerospace IEEE Conference. 2016.

114. Seidman SH. Translational motion perception and vestiboocular responses in the absence of non-inertial cues. Exp Brain Res. 2008; 184(1):13-29.

115. Selva P. Modeling of the vestibular system and nonlinear models for human spatial orientation perception. PhD dissertation. Université de Toulouse; 2009.

116. Small RL, Keller JW, Wickens CD, Oman CM, Jones TD. Modeling and Mitigating Spatial Disorientation in Low G Environments: Year 3 Report. NSBRI Project Number SA 01302. Cambridge, MA; 2010.

117. Small RL, Keller JW, Wickens CD, Oman CM, Jones TD. Modeling and Mitigating Spatial Disorientation in Low G Environments: A Progress Report. In: Eighth Symposium on Vestibular Research. 2011. p. 1.

118. Small RL, Keller JW, Wickens CD, Oman CM, Young LR, Jones TD, et al. Modeling and Mitigating Spatial Disorientation in Low G Environments: Year 1 Report. NSBRI Project Number SA 01302. Cambridge, MA; 2008.

119. Small RL, Keller JW, Wickens CD, Oman CM, Young LR, Newman MC, et al. Modeling and Mitigating Spatial Disorientation in Low G Environments: Year 2 Report. NSBRI Project Number SA 01302. Cambridge, MA; 2010.

120. St George RJ, Day BL, Fitzpatrick RC. Adaptation of vestibular signals for self-motion perception. J Physiol. 2011; 589(4):843-53.

121. van Der Steen H. Self-motion perception. PhD dissertation. Delft University of Technology; 1998.

122. Steinhausen W. Ueber die Beobachtung der Cupula in den Bogengangsampullen des Labyrinths des lebenden Hechts. Pflugers Arch Gesamte Physiol Menschen Tiere. 1933; 232:500-12.

123. Telban RJ, Cardullo FM. Motion cueing algorithm development: Human-centered linear and nonlinear approaches. NASA TechReport CR-2005-213747. Binghamton, New York; 2005.

124. Telban RJ, Cardullo FM, Houck JA. A Nonlinear, Human-Centered Approach to Motion Cueing with a Neurocomputing Solver. AIAA Model Simul Technol Conf Exhib. 2002; :1-10.

125. Telban RJ, Wu W, Cardullo FM, Houck JA. Motion Cueing Algorithm Development: Initial Investigation and Redesign of the Algorithms. 2000.

126. Tribukait A, Eiken O. On the role of otoliths and semicircular canals in spatial orientation: Dynamics of the visually perceived eye level during gondola centrifugation. Percept Psychophys. 2005; 67(7):1242-51.

127. Tribukait A, Eiken O. Semicircular canal contribution to the perception of roll tilt during gondola centrifugation. Aviat $\mathrm{Sp}$ Environ Med. 2005; 76(10):940-6.

128. Venkatesan RH. Multisensory Models for Human Spatial Orientation Including Threshold Effects. MSc thesis. Massachusetts Institute of Technology; 2010.

129. Venrooij J, Pretto P, Katliar M, Nooij SAE, Nesti A, Lächele M, et al. Perception-Based Motion Cueing : Validation in Driving Simulation. Driv Simul Conf. 2015; (3):153-61.

130. Vingerhoets RAA, van Gisbergen JA. MM, Medendorp WP. Verticality perception during off-vertical axis rotation. J Neurophysiol. 2007; 97(5):3256-68.

131. Vingerhoets RAA, Medendorp WP, van Gisbergen JAM. Time course and magnitude of illusory translation perception during off-vertical axis rotation. J Neurophysiol. 2006; 95(3):1571-87.

132. Vingerhoets RAA, De Vrijer M, van Gisbergen JAM, Medendorp WP. Fusion of visual and vestibular tilt cues in the perception of visual vertical. J Neurophysiol. 2009; 101(3):1321-33.

133. Wearne S, Raphan T, Cohen B. Effects of tilt of the gravito-inertial acceleration vector on the angular vestibuloocular reflex during centrifugation. J Neurophysiol. 1999; 81(5):2175-90. 
Review Article

134. Young LR. Optimal estimator models for spatial orientation and vestibular nystagmus. Exp Brain Res. 2011; 210(3-4):465-76.

135. Young LR. On visual-vestibular interaction. Fifth Symp role Vestib organs Sp Explor. 1970; NASA SP-31:205-10.

136. Young LR, Meiry JL. A revised dynamic otolith model. Aerosp Med. 1968; 39(6):606-8.

137. Young LR, Oman CM. Model for vestibular adaptation to horizontal rotation. Aerosp Med. 1969; 40(10):1076-80.

138. Young LR. Visually induced motion in flight simulation. Paper 16. AGARD-CP-249. In: AGARD Symposium on Flight Simulation. Brussels, Belgium; 1978.

139. Zacharias GL, Young LR. Influance of Combined Visual and Vestibular Cues on Human Perception and Control of Horizontal Rotation. Exp Brain Res. 1981; 41:159-71.

140. Zupan LH, Merfeld DM. An internal model of head kinematics predicts the influence of head orientation on reflexive eye movements. J Neural Eng. 2005; 2:S180-97.

141. Zupan LH, Merfeld DM, Darlot C. Using sensory weighting to model the influence of canal, otolith and visual cues on spatial orientation and eye movements. Biol Cybern. 2002; 86(3):209-30.

142. Zupan LH, Peterka RJ, Merfeld DM. Neural processing of gravito-inertial cues in humans. I. influence of the semicircular canals following post-rotatory tilt. J Neurophysiol. 2000; 84(4):2001-2015.

\section{ACKNOWLEDGEMENTS}

The views, opinions, and findings contained in this article are our own and should not be construed as an official Polish Air Force position, policy, or decision, unless so designated by other official documentation.

Cite this article as: Lewkowicz R. A Modelling Approach To The Human Perception Of Spatial Orientation. Pol J Aviat Med Bioeng Psychol 2016; 22(4): 27-42. DOI: 10.13174/pjambp.23.02.2018.03 